\title{
Public Health Approach on Multiple Myeloma Prevention in Nigeria
}

\section{Ogbonna Collins Nwabuko ${ }^{1-3 *}$, John Austin Chikezie ${ }^{4}$ and Oseikhuemen Adeboye Ejele ${ }^{5}$}

${ }^{1}$ Department of Hematology, Federal Medical Center, Umuahia, Abia State, Nigeria

${ }^{2}$ Department of Hematology, College of Health Science, Abia State University, Aba, Abia State, Nigeria

${ }^{3}$ Department of Public Health, Walden University, USA

${ }^{4}$ Department of Internal Medicine, Abia State University, Uturu, Nigeria

${ }^{5}$ Department of Hematology, Blood Transfusion and Immunology, University of Port Harcourt, Rivers State, Nigeria

\begin{abstract}
Background: Multiple Myeloma (MM) poses a diagnostic dilemma to health care providers in Nigeria, especially orthopedic surgeons, because of its skeletal related events (SREs) and the internists due to the end-organ failure associated with the disease. These challenges, coupled with lack of human capacity and facilities for early diagnosis, have worsened the outcome of the disease in Nigeria.
\end{abstract}

Objective: This study is an advocacy to establish multiple myeloma screening policy in all health institutions in Nigeria. It is also a behavior-change intervention to create awareness of MM among health-care providers and in the targeted audience.

Method: A public health campaign approach using theoretical behavioral change framework, health communication, marketing and public relations as components for diffusion of innovations. Two keywords (Public Health Campaign and MM) were used as search strategy to identify the PICO (Problem, Intervention, Comparison and Outcome) elements of the campaign questions. PubMed, Google scholar, Cochran Database Systematic Review, African Journal Online were used as the search databases. Systematic reviews published within the past 16 years were used in literature search. The inclusion and exclusion criteria were applied in the selection process while reviewing the theoretical models for the health behaviors of the target group.

Result: The expected outcomes of the innovation are to create awareness of MM among the targeted audience and health care providers; institutionalize MM screening policy in all health institutions in Nigeria and adopt periodic screening test for MM using the point-of-care testing (POCT). The hallmark of the result is to curb or eliminate the late diagnosis of MM in Nigeria.

Conclusion: This approach on MM prevention will create a new behavior in the targeted audience. It will increase the knowledge base of the disease, strengthen the MM screening policy in the health institutions, and reduce the disease burden in Nigeria. This will ultimately improve the quality of life and overall life-expectancy of the targeted population. It is strongly recommended that other cancer specialties could leverage on this framework to improve on cancer surveillance, database and prevention in Nigeria.

Keywords: Public Health Campaign; Multiple Myeloma; Prevention; Awareness; Nigeria

\section{Introduction}

Multiple Myeloma, otherwise known as plasma cell myeloma, is a hematological malignancy characterized by proliferation of abnormal plasma cells in the bone marrow leading to chronic bone pain, anaemia (shortage of blood), skeletal related events (such as osteoporosis, pathological fracture), chronic renal failure (i.e., renal myeloma) and other end-organ failures $[1,2]$. The term "cancer" by definition qualifies it as a non-communicable disease (NCD) [3].

Multiple Myeloma is one of the commonest hematological diseases of public health importance worldwide, especially in lowincome and low-middle-income countries (LICs/LMICs) of subSaharan Africa because of the racial disparity for the black population compared to their white counterpart $[3,4]$. It accounts for about $15 \%$ of all lymphoproliferative diseases and $1-2 \%$ of all cancers globally. In Nigeria, it is estimated to account for $8.2 \%$ of all haematological malignancies [5]. It has higher predilection in the elderly males than in their female counterparts. Like any other cancer, the etiology of $\mathrm{MM}$ is unknown, but previous epidemiologic studies on the disease have implicated several potential predisposing factors such as immunosuppressive conditions as HIV, bone marrow or organ transplantation, environmental exposures (i.e., pesticides, herbicides, asbestos, laxatives, hair dyes, ionizing radiations), occupational hazards and viral infections (i.e., Kaposi sarcoma Herpes virus, hepatitis C virus, Ebstein-Barr virus, mutated cytomegalovirus) just to mention a few [6].

In Nigeria, there is dearth of knowledge of multiple myeloma, and this has contributed to the poor case ascertainment. The diagnoses are usually made late after complications must have set in, leading to late commencement of therapy, poor prognosis, poor survival outcome (survival interval) and reduced life expectancy of people living with multiple myeloma in the region [7-11]. A recent study in Nigeria showed that only about $7.6 \%$ of diagnosed MM patients survive up to five years post-diagnosis [12]. This was far below estimated five years post-diagnosis period survival of $44.9 \%$ recorded by Surveillance Epidemiological End-Results (SEER) cancer statistics review of 1975-

*Corresponding author: Nwabuko OC, Department of Hematology, Federa Medical Center, Umuahia, Abia State, Nigeria, Tel: +234 706933 7998; E-mail: ogbollins2002@yahoo.com

Received September 24, 2018; Accepted September 29, 2018; Published September 30, 2018

Citation: Nwabuko OC, Chikezie JA, Ejele OA (2018) Public Health Approach on Multiple Myeloma Prevention in Nigeria. J Blood Lymph 8: 229. doi: 10.4172/21657831.1000229

Copyright: (C) 2018 Nwabuko OC, et al. This is an open-access article distributed under the terms of the Creative Commons Attribution License, which permits unrestricted use, distribution, and reproduction in any medium, provided the original author and source are credited. 
2007 in the USA [13]. By this analysis, it implies that Nigeria is over fifty years behind the United States of America in the management of multiple myeloma as at the year 2007.

The current SEER cancer statistics review for five years postdiagnosis survival in the USA has risen to $50.7 \%$ (i.e., additional $5.8 \%$ increment) making the condition in Nigeria more worrisome [14]. The current new cases and deaths of people living with MM per 100,000 are 6.7 per 100,000 and 3.3 per 100,000 men and women respectively. There were an estimated 124,733 people living with MM in the USA in 2015 [14]. In Nigeria, Africa's most populous nation with a population size of 166.6 million people and annual growth rate of 3\%, it is estimated that MM accounts for about 1021 out of 102,100 of newly diagnosed cancers annually [15]. It is estimated that approximately 0.8 per cent of men and women will be diagnosed with $\mathrm{MM}$ at some point during their life. While the case fatality index (CFI) of people living with MM in the USA is about 59.5 per cent, that for their counterpart in Nigeria is about $93.1 \%$ [13].

Based on these findings, a public health campaign on awareness and screening tests for MM in the targeted audience became necessary in Nigeria. Public health campaign is chosen because it is a health promotion initiative. It is the most favourable medium through which public health messages can be disseminated to bring about the desired behavioural changes in the target audience. This campaign aims to increase the knowledge base of multiple myeloma among the targeted audience and health care providers through institutionalizing MM screening policy in all health centres in Nigeria, and periodic screening for multiple myeloma (about 3-6 monthly) on the targeted audience. This campaign is expected to run for a period of three years in order to bring about the desired changes.

It is expected to start from tertiary health centres in first fiscal year (FY), the secondary and primary health centres in the second and third fiscal years respectively.

The objectives of this campaign are:

- To reduce the onset of diagnosis of MM from 2 years to $<6$ months (early detection or diagnosis of multiple myeloma) Nigeria.

- To establish multiple myeloma screening policy in all health institutions in Nigeria starting with the tertiary health centres in FY1, the secondary and primary health care centres in the FY2 and FY3 respectively.

- To establish a MM registry in all health institutions for case ascertainment and subsequent surveillance of multiple myeloma locally and nationally (Surveillance Epidemiologic End-Result, SEER biostatistics for MM in the sub-Saharan).

- To reduce multiple myeloma-related complications by half of current values (i.e., reduction of prevalence of severe anaemia from current $50 \%$ to $25 \%$ among people living with multiple myeloma in Nigeria).

- To improve the five years post-diagnosis survival from $7.6 \%$ to $40 \%$.

\section{Methodology \\ Campaign design}

This proposed multi-centred public health awareness campaign is an observational prospective study. It is expected to run over a period of three years which will be subdivided into twelve quarters (Q1-Q12).

\section{Target group and settings}

The target audience includes middle to elderly aged population who reside in Nigeria. Their estimated average age range is 40 years and above. This target group who present commonly with features suggestive of MM in the region is termed the 'perceived susceptible group'. They make up about 12.7\% (about 21 million based on 2006 population census) of the total population of Nigerians [16]. Previous studies are in keeping with the above target group as the high risk group for MM $[12,17]$. This campaign will also target health professionals in its educational session. This will help to update them on the perceived severity they should look out for in order to make a presumptive diagnosis of multiple myeloma. It is expected that this will help to resolve the long-standing diagnostic dilemma associated with $\mathrm{MM}$ among health care providers in Nigeria. The target audience is therefore a combination of people with different levels of health literacy, and so this must be taken into cognizance while crafting communication strategies and in the diffusion of the innovations on the screening test for multiple myeloma.

\section{Planning model}

The campaign messages serve dual purposes. The first is as an advocacy to establish multiple myeloma screening policy in all health institutions in Nigeria, while the second as a behaviour-change intervention to create awareness of MM with the ultimate goal as to adopt periodic screening tests for MM in the targeted population [18].

This will be achieved using communication tools such as television, radio, social media (social networking), billboards, seminars, conferences, and other tools that are familiar with the targeted audience [19]. The FY-1 will target the tertiary health care level. The FY-2 will target the secondary health care level while the FY-3 will target the primary health care level, all in a quarterly fashion per fiscal year.

This public health campaign will be implemented using the 'wheel concept model' [20]. This concept applies six fundamental mechanisms to drive effective public health program implementation. These include innovation, technical package intervention, performance management, partnership, and political commitment. Figure 1 illustrates the wheel concept approach. The "innovation" in this context is the central hub that drives the wheel (i.e., it is the new concept or intervention to counteract the social crises which is $\mathrm{MM}$ in this case); while the

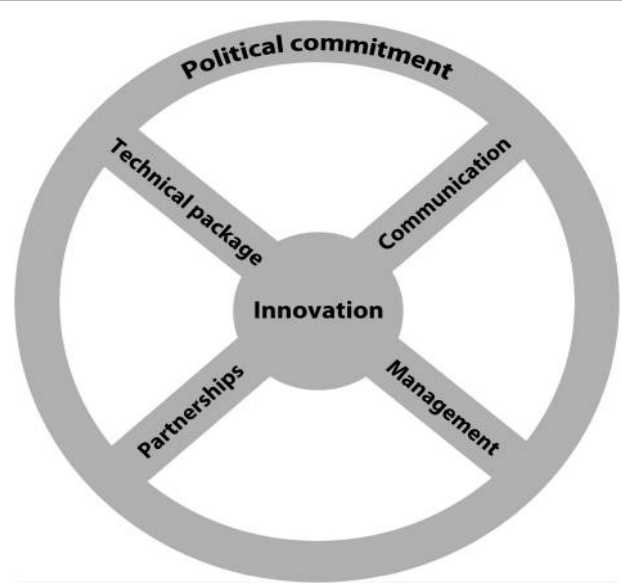

Figure 1: The Wheel Concept Model. 
political commitment gives resources and support (i.e., funding which represents the tube or tyre in this concept). In this model, the technical package to achieve the desired change, the communication tools to convey the message to the targeted audience and the performance management which is basically monitoring and evaluation collectively form the spokes of the wheel.

The technical package in this campaign include the expected actions to bring about the behaviour changes and these are:

- Periodic screening for MM (3-6 monthly) with or without clinical features of MM.

- Screening test for MM when clinical features of MM are seen.

- Establishment of a healthcare policy that will make multiple myeloma screening test of targeted audience mandatory in all health institutions in Nigeria.

- Avoidance of risky behaviours (predisposing factors) that will predispose the targeted group to MM.

In carrying out this campaign, the value of partnership cannot be over-emphasized. There is a need for involvement of local, international (non-governmental agencies (NGOs), civil service organizations (CSOs) and community-based participatory research groups, CBPRs).

In communicating the targeted audience, it is particularly important to direct the messages in such a way that it will be meaningful to them. The two ways to promote public relation in the target audience are by:

Engaging them on social media or common communication tools - This is by engaging the target audience who are active on social media in social networking such as blog, Facebook, YouTube, flicker etcetera. These may be preferable because of their cost-effectiveness. Engaging them in conversations on presumed definition and severity of multiple myeloma and how it can be detected may emotionally appeal to them to change their behaviours [21]. On the other hand, for those who are not active in social media, a periodic interactive forum in radio or television might be contributory. Radio adverts such as "issues of the moment," "radio jingles" and "health perspectives" could be useful strategies of intervention [19]. The social media is currently a robust global communication tool, providing interventions for high risk preventable health behaviours including multiple myeloma and other forms of cancers in the world [22].

Speaking at events such as conferences could be a great way of getting to the targeted audience. This becomes more expedient if the subject of discussion has to do with the public health campaign as in the case of multiple myeloma awareness campaign.

\section{Campaign theory}

Theory can be defines as a set of interrelated concepts which can explain situational problem and predict the target intervention for the problem. It is usually used in public health to proffer solutions to health behavioural problems. In other words, it can be said to be antidote to some harmful health practices. Most public health campaign messages uses behavioural theoretical models to bring about the desired health changes in the targeted audience [23].

There are different types of health behavioural theories in public health. However, for this public health campaign, the Health Believe Model (HBM) is the most favoured theory. It is so chosen because it is the most favoured theory for cancer intervention [24].

The Health Believe theoretical Model uses four perceptions in its evaluation of the target interventions. They are Perceived Susceptibility, Perceived Severity, Perceived Benefit and Perceived Barrier [25]. The campaign theory can be illustrated by using Table 1 .

\section{Resources}

These are the tools that will enable smooth and successful execution of the public health campaign. They include government commitment in providing support and enacting health promoting policies that will improve the quality of life of the targeted group. In this case, the government has a role in successful execution of this campaign by ensuring that the MM screening policy will scale through in all health institutions in Nigeria. This will be achievable through funding the bill and provision of all health facilities necessary for education, information dissemination and screening for $\mathrm{MM}$ in the targeted audience [26,27].

Other resources would be provided by the community through the CBPR groups, the NGOs, CSOs, philanthropists, local and foreign donor agencies who can partner with the government to promote this public health initiative $[20,28]$.

\section{Time frame}

The time frame for this public health campaign is documented in the campaign statement in the objectives. This campaign will be for duration of 3 years starting from tertiary health centres in first fiscal year (FY), the secondary and primary health centres in the 2nd and 3rd FY respectively.

\begin{tabular}{|l|l|l|}
\hline Serial No & Perception & Target Intervention \\
\hline 1 & Perceived susceptibility & $\begin{array}{l}\text { Educating targeted group about multiple myeloma, the clinical presentation such chronic back or bone pain (>1 month), anaemia, } \\
\text { pathological fracture or weight loss. }\end{array}$ \\
\hline 2. & Perceived severity & $\begin{array}{l}\text { The complications of multiple myeloma such as transfusion-dependent anaemia, chronic renal failure requiring dialysis or kidney } \\
\text { transplant, pathological fracture requiring orthopaedic intervention, osteoporosis, the burden of treatment of the disease and death. }\end{array}$ \\
\hline 3. & $\begin{array}{l}\text { Early screening will give rise to: } \\
\text { - Early detection (diagnosis) and disease prevention } \\
\text { - Early therapy } \\
\text { - Complication prevention } \\
\text { - Improved QOL and overall survival interval } \\
\text { - Improved life expectancy of target group } \\
\text { - Institutionalizing periodic screening test for myeloma of the target group in all health centres in Nigeria. (Policy). } \\
\text { - Use of social marketing theory as a strategy of health promotion for multiple myeloma screening in Nigeria. } \\
\text { - Use of public relations as a strategy to appeal to the targeted group. }\end{array}$ \\
\hline 4. & Perceived Barrier &
\end{tabular}

Table 1: Tabular illustration of MM campaign theory. 
The monitoring and evaluation of this project are to be carried out monthly and quarterly using the MM cancer registries that will be established at the various health centres of the campaign sites in Nigeria. By so doing it will help the evaluators to know if changes or improvements occur as a result of the intervention [28].

\section{Budget plan}

The campaign budget plan will look into two major items: the capital and the recurrent expenditures. The capital expenditure will include the cost of purchasing items for field operations, computers, stationeries and other items which are deemed to fall within this category.

The recurrent expenditures will take into cognizance personnel (staff and consultants salaries), trainings, travels, supplies, communication tools, screening tests, maintenance and other contingencies.

\section{Ethical Issues about the campaign}

Looking at the campaign from the perspective of Communitybased Participatory Research (CBPR), ethical issues are standards which could be policies, procedures or rules put in place to ensure that the interests of the participants in research are adequately protected. They are more like the legal permission a researcher gets before his study is put into the field. Two key players are responsible for giving this permission. They are the participant (target audience in this context) and the Institutional Review Board (IRB). While the researcher gets an informed consent from the participants in the research, he gets ethical clearance from IRB to proceed with the study. The two permissions must be provided before field work can advance. In this study, consent must be sought from the targeted audience, because of the autonomy of the patient based on the Public Health Code of Ethics Article 25. There is the possibility that some of the patients from the target group may refuse to sign the consent form. In situations where the patients refuse to sign the consent, measures must be put in place to gain their trust [29].

\section{Evaluation Plan and Discussion of Outcomes}

Public health campaign implementation is all about improving the health outcomes of the target audience they seek to serve. As such the campaign's performance management is of paramount importance. And this involves monitoring and evaluation of improvement and change in the behaviour of the target audience. The top priorities of this campaign are to reduce the period of onset of diagnosis of multiple myeloma (i.e., increase early diagnosis) from 2 years to less than six months in Nigeria. To imbibe MM screening culture among the targeted audience, as evidenced by an increase in the number of target audience presenting for the routine periodic bone marrow cancer screening test in Nigeria. This will be achieved through surveillance (Bone marrow cancer screening registry in every hospital).

To increase the number of health institution where bone marrow cancer screening test policy have been implemented. This campaign approach will be Specific (i.e., MM), Measurable (i.e., a goal obtainable campaign with 3 years expected time of completion), Achievable with all stakeholders, Realistic, Time-bound (3 years), and Ethical (i.e., no intention to do any harm or violate human rights). To evaluate this implementation, the use of RE-AIM concept is strongly recommended. RE-AIM means Reach, Effective, Adoption, Implementation, Maintenance $[19,20,22]$. This means there is a need to reach out to the target population who want to participate in this intervention; measure the impact (effectiveness) of the intervention on important outcomes of the target audience; track the number of target audience willing to implement the intervention; and those who have completely changed (i.e., implemented the intervention). The last approach is a long-term evaluation of the level of sustenance of the new behaviour [30,31].

One major way the target audience may adopt this public health approach is by social marketing of the behavior change. The three ways of marketing behavioral change to the target audience include:

- Emotional appeal - This means using "consequences of risky behavior" to appeal or send your message to the target audience. This can be executed by using unexaggerated real-life testimonies (fear appeal) of "MM patients who died because the diagnoses were made late" to appeal to the emotions of the target audience [21] It may be tagged as "I wish I did my Bone marrow cancer screening" or "I wish I screened for MM". This method connects you to your target audience quickly, and it is useful in screening tests $[32,33]$.

- Using Celebrities: Considering the target audience, it is recommended that celebrities who genuinely have passion for people who have cancer (MM) be used to offer breakthrough voice. However, there is a need to exercise caution on the credibility of the "celebrity endorser" as the impact the campaign message will make on the target audience will necessarily depend on that.

- By engaging the target audience in activities that will help them to achieve the positive change. This may be more preferable than telling them what to avoid. It may warrant recognizing or sending some gifts to those who successfully carried out their screening tests routinely annually.

In order to actualize the objectives of this campaign, the following strategies must be implemented:

1. Community involvement and mobilization by recruiting operational and supportive staff in the six geopolitical zones of Nigeria who will be able to get to their target audience in their zones. This is by liaising with community heads, CSO and CBOs. Streets campaign by supportive and operative groups, CSOs, CBOs, celebrities, NGOs, and governmental agencies. Radio and television interviews will be favorable forums to create awareness.

2. Training of the staffs on their expectations including how to give health talks on the clinical presentations of MM to the targeted audience, basic skills on how to screen for MM in a patient, and on documentation (i.e., MM cancer registries).

3. Technology transfer of the innovation which includes screening of adopted targeted audience which commences after mobilization and training.

4. The CBPR members will collaborate with the haematology and public health research departments of each health institution for update on data collection using the local MM cancer registries.

5. The number of institutions where MM screening policies are established with evidence of cancer registries will be assessed. Similarly, the number of target audience that come for screening test, the number of diagnosis of MM made and the stage at diagnosis will be recorded on weekly, monthly, quarterly, and annual bases.

\section{Conclusion}

The public health approach on MM prevention in Nigeria entails 
Citation: Nwabuko OC, Chikezie JA, Ejele OA (2018) Public Health Approach on Multiple Myeloma Prevention in Nigeria. J Blood Lymph 8: 229. doi: 10.4172/2165-7831.1000229

education and screening for $\mathrm{MM}$ in the targeted audience. These innovations could be diffused through proper communication network, evaluation, partnership and political commitment. This approach has the capacity of primary prevention of MM in the target group. It also has the capacity for early disease detection (diagnosis), improved case ascertainment and early therapeutic intervention. These will ultimately lead to reduction of complications of MM in the target audience and improved life expectancy of people living with MM in Nigeria. It is, therefore, strongly recommended that other cancer specialties should leverage on this framework to improve on cancer surveillance, care and prevention in both the sub-Saharan African region and the world at large.

\section{References}

1. Bataille R, Harousseau JL (1997) Multiple myeloma. N Eng J Med 336: 16571664.

2. Alexander DD, Mink PJ, Adami H, Cole P, Mandel JS, et al. (2007) Multiple myeloma: a review of the epidemiologic literature. Int J Cancer 120: 40-61.

3. Parkin DM, Whelan SL, Ferlay J, Teppo L, Thomas DB (2002) Cancer in Five Continents. Vol. VIII. IARC Sci Publ pp: 1-781.

4. Parkin DM, Bray F, Ferlay J, Pisani P (2002) Global cancer statistics. CA Cancer J Clin 55: 74-108.

5. Landgren O, Kyle RA, Pfeiffer RM, Katzmann JA, Caporaso NE, et al. (2009) Monoclonal gammopathy of undetermined significance (MGUS) consistently precedes multiple myeloma. A prospective study. Blood 113: 5412-5417.

6. Becker N (2011) Epidemiology of multiple myeloma. Recent Results Cancer Res 183: 25-35.

7. Nwabuko CO, Nnoli MA, Okoh DA, John EJ, Chukwuonye II (2015) Survival outcome of multiple myeloma patients on chemotherapeutic regimens in the Niger-delta Nigeria. Int J Recent Sci Res 6: 4889-4893.

8. Salawu L, Durosimi MA (2005) Myelomatosis: clinical and laboratory features in Nigeria. West Afr J Med 24: 54-57.

9. Nnonyelum ON, Anazoeze MJ, Eunice NO, Emmanuel OO, Stella AT, et al. (2015) Multiple myeloma in Nigeria: A multi-centre epidemiological and biomedical study. Pan African Medical Journal 22: 292.

10. Omoti C, Halim NKD (2007) Plasma cell myeloma in a Tertiary Center in NigerDelta Region of Nigeria: Clinico-immunologic analysis. Pak J Med Sci 23: 27-32.

11. Fasola FA, Eteng K, Akinyemi JO (2008) Multiple myeloma: challenges of management in a developing country. J Med Med Sci 397-403.

12. Nwabuko O, Igbigbi E, Chukwuonye I, Nnoli M (2017) Multiple myeloma in Niger Delta Nigeria: complications and the outcome of palliative interventions. Cancer Manag Res 2017: 189-196.

13. Altekruse SF, Kosary CL, Krapcho M (2018) SEER Cancer Statistics Review. 1975-2007. Bethesda: National Cancer Institute; 2010.
14. Howlader N, Noone AM, Krapcho M (2018) SEER Cancer Statistics Review, 1975-2014. Bethesda: National Cancer Institute.

15. Ferlay J, Shin HR, Bray F, Forman D, Mathers C, et al. (2010) Estimates of worldwide burden of cancer in 2008: GLOBOCAN 2008. Int J Cancer 127: 2893-2917.

16. National Population Census.

17. Madu AJ, Ochenis S, Nwagha TA, Ibegbulam OG, Anike US (2014) Multiple myeloma in Nigeria: an insight to the clinical, laboratory features, and outcomes. Niger J Clin Pract 17: 212-217.

18. Raab M, Rocha J (2011) Campaign to End Violence against Women and Girls United Nations Entity for Gender Equality and the Empowerment of Women

19. Hall I, Johnson-Turbes A, Williams $K$ (2010) The potential of black radio to disseminate health messages and reduce disparities. Prev Chronic Dis 4: 1-6.

20. Thomas RF (2014) Six Components Necessary for Effective Public Health Program Implementation. Am J Public Health 104: 17-22.

21. Resnick E, Siegel M (2013) Marketing public health: Strategies to promote social change (3rd edn). Burlington, MA: Jones \& Bartlett Learning.

22. Pew Research Center (2013) Majority of Adults look Online for Health Information.

23. Glanz K (2002) Perspectives on using theory. In: Health Behavior and Health Education Theory, Research, and Practice. San Francis: Jossey-Bass.

24. Doumit M, Fares S, Arevian M (2017) Knowledge of Women Towards Breast Cancer in Lebanon. Amer J Hematol Oncology 13: 21-28.

25. Glanz K, Rimer BK, Viswanath K (2015) Health behavior: Theory, research, and practice (5th edn). San Francisco, CA: Jossey-Bass.

26. Health policy project/Nigeria.

27. Hunter DJ (2009) Leading for Health and Wellbeing: the need for a new paradigm. J Public Health 31: 202-204.

28. Springett J (2003) Issues in participatory evaluation. In: Minkler M, Wallerstein $\mathrm{N}$ editors. Community Based Participatory Research for Health. New York: Jossey-Bass; 2003:263-86.

29. Public Health Leadership Society (2002) Principles of the Ethical Practice of Public Health.

30. Gaglio B, Shoup JA, Glasgo RE (2013) The RE-AIM Framework: A Systematic Review of Use Over Time. Am J Public Health 103: e38-e46.

31. Coady MH, Jasek J, Davis K, Kerker B, Kilgore EA, et al. (2012) Changes in smoking prevalence and number of cigarette smoked per day following the implementation of a comprehensive tobacco control plan in New York City. J Urban Health 89: 802-808.

32. Finset A (2011) Risk perception and risk communication. Patient Educ Couns 82: $1-2$.

33. Paivio A (1986) Mental representations. A dual coding approach. New York Oxford University Press. 